Revista Monografias Ambientais

Santa Maria, Santa Maria, Edição Especial Curso de Especialização em

Educação Ambiental. 2015, p. 133-143

Revista do Centro de Ciências Naturais e Exatas - UFSM

ISSN : 22361308

\title{
Um Olhar Sobre a Educação Ambiental na Região do Saladeiro, Quaraí-RS
}

\author{
A View Upon Environmental Education In Saladeiro Region, Quaraí-RS
}

\author{
Gisele de Castro Mazzuhy'; ${ }^{1}$ Cibele Rosa Gracioli²
}

${ }^{1}$ Bióloga, Especialista em Educação Ambiental, UFSM, Santa Maria,RS, Brasil - E-mail: gisele.cm25 @gmail.com (autora), Aluna do Curso de Especialização em Educação Ambiental ²Engenheira Florestal e Doutora em Engenharia Florestal, UFSM, Santa Maria, RS, Brasil - E-mail: cibelegracioli@gmail.com (orientadora)

\section{Resumo}

Tendo em vista a relevância do bairro Saladeiro para as comunidades de Quaraí, no Rio Grande do Sul, e Artigas, no Uruguai, é de grande importância para a região um Projeto Binacional que busque potencializar ações de conscientização ambiental em ambos os países. A proposta de ações que possam minimizar os possíveis problemas ambientais e de saúde, ocasionados pelo acúmulo de resíduos sólidos e de água parada, possibilita uma melhoria na qualidade de vida da população local. O objetivo desse trabalho foi realizar um levantamento da atual percepção dos moradores do entorno e dos alunos de uma Escola Pública em relação às questões ambientais, para sugerir propostas de melhoria na qualidade do ambiente. As ações propostas consistiram em palestras, folders educativos e a proposta para o mutirão de limpeza às margens do Rio Quaraí. Em relação aos resultados obtidos verificou-se que os alunos e os moradores têm consciência sobre os problemas ambientais e de saúde. Pode-se concluir que, em relação à percepção dos problemas ambientais, tanto os moradores quanto os alunos estão cientes do problema e entendem que ações a pequeno, médio ou longo prazo geram consequências, ou seja, se o ambiente for limpo e saudável, não haverá vetores de doenças e não será um fator que irá colaborar com enchentes. A partir das propostas de melhoria, tanto os moradores quanto os alunos estão dispostos a colaborar para com as mesmas, demonstrando isso no interesse em preservar o Rio Quaraí, que tinha como proposta a limpeza das margens que não foi possível devido a problemas com datas disponíveis e com as chuvas que prejudicou esta atividade, entretanto, pelo lado Uruguaio o projeto obteve êxito.

Palavras-Chave: Resíduos, Conscientização Ambiental.

\section{Abstract}

Given the relevance of Saladeiro neighborhood to the communities of Quaraí-RS and Artigas, Uruguay, it's of great importance to the region a Bi-national Project that seeks to enhance environmental awareness actions in both countries. The proposed actions that may minimize the possible environmental and health problems caused by the accumulation of solid waste and stagnant water, allow an improvement in the quality of life of local people. The aim of this study was to survey the current perception of the surrounding residents and students from a public school in relation to environmental issues, to suggest proposals for improvement in the quality of the environment. The proposed actions consisted of lectures, educational folders and the proposal for the task force to clean the banks of the River Quaraí. Regarding the results obtained it was found that students and residents are aware of the environmental and health problems. It can be concluded that in relation to the perception of environmental problems both residents and students are aware of the problem and they understand that short, medium, or long term actions generate consequences, that is, if the environment is clean and healthy there won't be disease vectors and it won't be a factor that will collaborate with floods. From the improvement proposals, both residents and students are willing to cooperate with them, this being demonstrated through the interest in preserving the River Quaraí that had as proposal the cleaning of the banks that was not possible due to problems with dates available and the rains that wronged this activity, however, on the Uruguayan side the project was successful.

Keywords: Waste, Environmental Awareness. 


\section{Introdução}

A água é um bem de uso comum, sem a informação e a conscientização, esse recurso poderá se tornar escasso em pouco tempo, gerando problemas ambientais, sociais e econômicos.

Considerando-se o caráter transfronteiriço do Rio Quaraí, cabe ressaltar os fortes impactos sofridos com a poluição, especialmente junto às áreas urbanas de Quaraí (Brasil) e Artigas (Uruguai). Os usos múltiplos dessas águas exigem controle de qualidade e controle do nível do Rio. A Educação Ambiental da comunidade em relação a gestão dos resíduos sólidos se apresenta como uma forma de preservação da área. Com a criação de novos hábitos pode-se contribuir para a construção de uma sociedade mais consciente, mas civilizada, mais atenta, mais comprometida e "mais limpa".

Segundo Volkmer (2007), na cidade de Quaraí, localizada à margem direita do rio de mesmo nome, limite geopolítico entre o Brasil e o Uruguai, encontram-se ainda hoje alguns vestígios materiais da expansão industrial pecuarista acontecida no Rio Grande do Sul ao findar o século XIX. Este estudo sobre o saladeros e saladeristas da região da Fronteira Oeste do estado teve origem nos questionamentos realizados - e na ausência de respostas - diante das impolutas ruinas do saladeiro São Carlos.

A região do Saladeiro, Quaraí, RS, é um local potencialmente turístico, sendo uma atração turística binacional, justificando, um trabalho de educação e conscientização para tornalo um local limpo e saudável visto que, doenças como a dengue, por exemplo, podem se propagar na presença de resíduos no ambiente.

Lyle (1994) apud Menegat, et al, (2004) (p. 268) afirma que os Resíduos são encarados de forma diferenciada da que usualmente é feita. Normalmente, os resíduos são definidos como materiais sem valor e que devem ser jogados fora após o uso. Esse tipo de definição foi o homem quem criou, já que a natureza processa os resíduos de forma cíclica, sempre retornando para o sistema os resíduos que venha a produzir.

A falta de coleta e da disposição final adequada dos resíduos sólidos favorece a proliferação, por exemplo,de ratos, aves (urubus e garças), suínos, cachorros e gatos, destacadamente no local de disposição final. Sendo assim, existe a possibilidade de que os casos de cisticercose, leptospirose, teníase, toxoplasmose e triquinose estejam associadas a proliferação destes. Quanto menor o orçamento municipal destinado ao serviço de limpeza urbana maiores são as chances de ocorrerem doenças entre a população exposta a estes (DEUS, 2004).

A Secretaria de Saúde e Vigilância Sanitária e Meio Ambiente da Prefeitura Municipal de Quaraí, Emater juntamente com a Companhia Riograndense de Saneamento (CORSAN), estão atuando juntas com a finalidade de trabalhar a questão da educação ambiental, enfocando a problemática dos resíduos sólidos, despertando o cidadão para sua responsabilidade sobre a questão, em ações para a limpeza das margens do rio ressaltando a importância para a saúde, visto que, foram detectados no local, 59 focos do mosquito Aedes aegypti na cidade.

Os estudos ecológicos procuram avaliar como os contextos social e ambiental podem afetar a saúde de grupos populacionais. Neste caso, as medidas coletadas no nível individual são incapazes de refletir adequadamente os processos que ocorrem no nível coletivo.

Por exemplo, o nível de desorganização social de uma comunidade pode contribuir para que uma determinada epidemia ocorra de maneira mais intensa. (MEDRONHO. et al, 2009).

Silva (2012) apud Meadows (1996) afirma que "desde o primeiro o momento em que os seres humanos começaram a interagir com o mundo ao seu redor, e ensinaram seus filhos a fazerem o mesmo, estava havendo educação e educação ambiental". Após o processo de urbanização e industrialização a percepção de que a educação ambiental se faz presente em nosso dia-a-dia começou a mudar, o mundo começou um modelo de "desenvolvimento insustentável", pois não importava o destino dos resíduos químicos, sendo estes da indústria ou das residências, todos eram despejados nos rios, nas matas, no meio ambiente em geral. 
Segundo Carvalho (2004), é evidente que, ao constituir-se como prática educativa, a E.A também se filia ao campo da educação propriamente dito e é da confluência entre o campo ambiental e algumas tradições educativas que vão surgir orientações específicas dentre da E.A.

O objetivo geral deste trabalho é contribuir para a melhoria da qualidade de vida da população e sua inter-relação com o meio ambiente, diminuindo os impactos sofridos com a poluição nas margens do Rio Quaraí junto às áreas urbanas de Quaraí e Artigas na localidade do Saladeiro afim de, apresentar ações de educação ambiental junto aos órgãos ambientais, que envolvam a população, no intuito de promover a melhoria da qualidade do ambiente na região turística do Saladeiro, em Quarai, RS.

O trabalho tem os seguintes objetivos específicos: Estabelecer contato com órgãos e entidades de abrangência municipal, estadual e Federal para fazer parceria na execução de parte do projeto; Fazer um diagnóstico da situação ambiental, através da aplicação de questionários; Proferir palestras feitas para a comunidade e aos alunos de uma escola, abordando a importância da preservação, juntamente com distribuição de folders informativos; Promoção de um mutirão de limpeza das margens do Rio Quaraí, junto com os órgãos ambientais e entidades envolvidas, propiciando a qualidade estética e ambiental do local.

\section{Metodologia}

O trabalho foi desenvolvido no município de Quaraí, RS, localizada a margem direita do rio de mesmo nome limite geopolítico entre o Brasil e o Uruguai, no bairro Saladeiro, com acesso através da Rua AscânioTubino, direção oeste, no período de junho a outubro do ano de 2014.

Este estudo contou com o apoio de órgãos tais como a Secretaria de Saúde e Vigilância Sanitária e Meio Ambiente da Prefeitura Municipal de Quaraí, e a Companhia Riograndense de Saneamento (CORSAN), a Empresa de Assistência Técnica e Extensão Rural/RS (EMATER/RS) e Exército Brasileiro (5 Regimento de Cavalaria Mecanizado com a Denominação Histórica de "CAVALARIA DA LEGIÃO DE TROPAS LIGEIRAS").

A escola escolhida para ser analisada foi a Escola Municipal de Ensino Fundamental Emílio Callo no bairro Saladeiro, Quaraí-RS. Nessa escola estavam presentes 39 alunos que responderam ao questionário e ouviram a palestra. Essa ação foi desenvolvida com a comunidade com uma conversa informal sobre os temas propostos no questionário em 68 casas com os proprietários e demais familiares presentes em muitas.

O trabalho constou de quatro fases enumeradas a seguir:

$1^{\text {a }}$ Fase: Contato com a Vigilância Sanitária, Secretaria Municipal de Meio Ambiente e Secretaria de Obras do Município. Afim, de combinar o trabalho de limpeza das margens do Rio Quaraí.

A vigilância atua junto no trabalho de prevenção e combate a dengue, a Secretaria de Meio Ambiente auxiliou junto a CORSAN e a Vigilância a mapear os pontos críticos para a limpeza e demarcar a área do exercito, CORSAN, escoteiros, e demais funcionários da prefeitura municipal para a limpeza.

$2^{a}$ Fase: Contato com alunos da E. E. E.F. Emílio Callo e diagnóstico da situação por meio de questionários e uma palestra e entrega dos folders na data de 25 de junho de 2014. Afim, de trocar conhecimento e saber mais como ocorre o descarte do lixo em casa e o que eles sabem das conseqüências.

$3^{\mathrm{a}}$ Fase: Contato com a comunidade da região primeiramente com a presidente do bairro após com o conhecimento da mesma foi dado início a uma conversa informal e os questionários com as pessoas que estavam em casa e entrega dos folders em 68 domicílios nas Ruas AscânioTubino, 26 de março, Negrinho do Pastoreio, São Carlos, Baicurus, Guaicurus, Bernardino Machado, Corredor municipal e São João Batista do Quaraí.

$4^{\mathrm{a}}$ Fase: Limpeza das margens do Rio Quaraí

A limpeza das margens teria a colaboração do exército, CORSAN, EMATER, Vigilância Sanitária, Agentes Comunitários, Parque de Máquinas, Escoteiros, e se possível devido ao ano letivo alunos. Entretanto, apesar dos esforços e interesse dos colaboradores devido às chuvas que ocorreram nos últimos meses não foi possível realizar esta limpeza nas margens. 


\section{Resultados e Discussão}

Em relação ao Contato com os órgãos públicos (primeira fase) chegaram-se aos seguintes resultados: Os órgãos públicos têm interesse em realizar a atividade de limpeza das margens.

Em relação à aplicação do questionário na Escola (segunda fase) chegaram-se aos seguintes resultados:

Na pergunta1 - Existe acúmulo de lixo em sua comunidade?

Todos os entrevistados foram unânimes em dizer que existe problema de acúmulo de lixo na comunidade, que o lixo vem tanto da comunidade do Saladeiro quanto de outras comunidades (bairros). Os tipos de resíduos encontrados são: móveis, eletrônicos, ferro, plástico, vidros, restos de podas de árvores, restos de construção, lâmpadas, baterias de carro, animais mortos, pilhas, pneus, latas, restos de cerca, calçados, roupas, aparelhos de telefone, etc. (Figura 1).

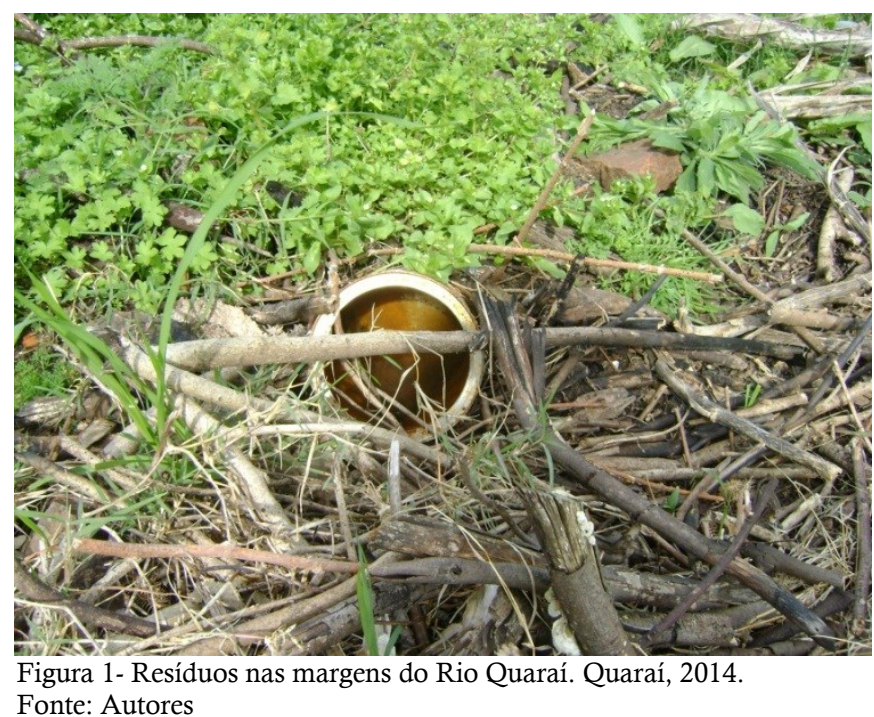

Em muitos terrenos, corredores e na ponte é comum encontrar resíduos descartados pelos moradores e por pessoas de outras localidades (Figura 2).

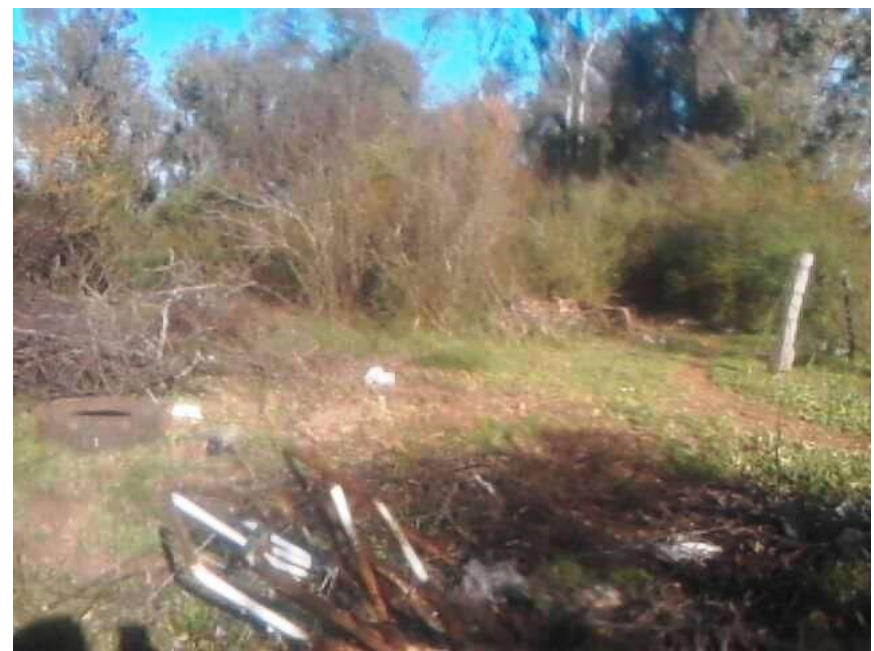

Figura 2 - Resíduos encontrados em terrenos no bairro Saladeiro. Quaraí, 2014. Fonte: Autores

Na pergunta 2- Quantas pessoas moram na residência?

As respostas foram as seguintes: em 6 casas morava apenas 1 pessoa, em 11 casas 2 pessoas, em 19 casas 3 de a 4 pessoas, 8 casas haviam 5 pessoas , 4 casas 6 pessoas e em apenas 1 
casa 7 pessoas ou seja se em cada casa uma pessoa passar o assunto que foi comentado no questionário e se lerem o folder com atenção esse assunto poderá ser multiplicado.

Na pergunta 3 - Existe problema de acúmulo de lixo na comunidade?

Para a maioria, existe o problema do acúmulo do lixo, para os demais, por exemplo, que vivem no final da Rua São João Batista, do Quarai e alguns casos isolados, esse problema é inexistente (Figura 3).

\section{Existe acúmulo de lixo em sua comuniade?}

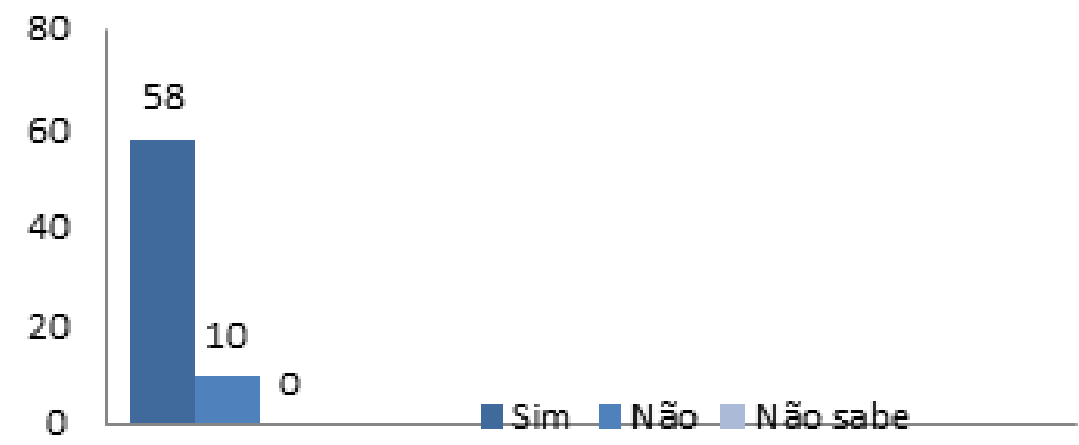

Figura 3 - Resposta da pergunta 3 em relação ao acúmulo de lixo na comunidade do Saladeiro. Quaraí, 2014. Fonte: Autores

Na pergunta 4 - Esse lixo é da comunidade ou está vindo de outras localidades?

Conforme a figura 4, esses resíduos provêm de outras comunidades (outros bairros).

\section{Esse lixo é da comunidade ou está vindo de outras localidades?}

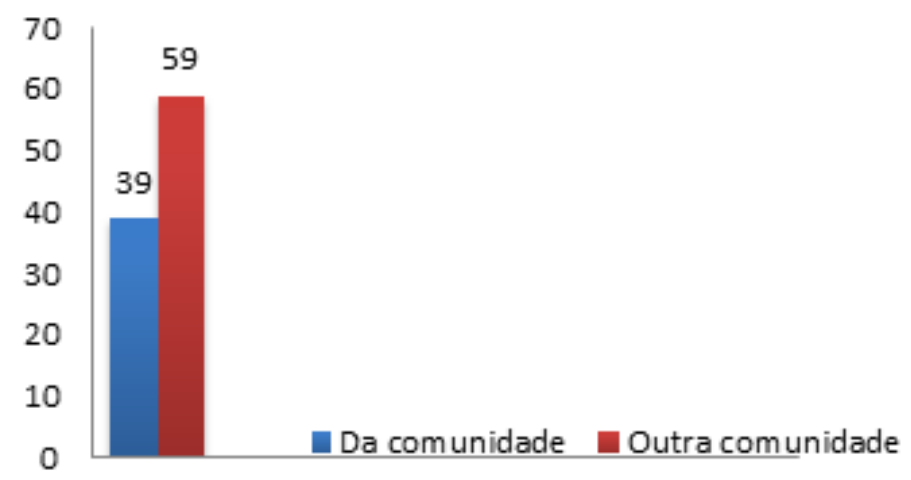

Figura 4 - Resposta da pergunta 4 em relação aos resíduos que aparecem na comunidade do Saladeiro. Quaraí,2014.

Fonte: Autores.

Os locais mais citados onde se encontra o lixo são na ponte do Saladeiro, nas Ruinas, corredores e ao redor do bairro.

Na pergunta 5 - Que tipos de resíduos são encontrados na comunidade?

A maioria dos moradores diz que têm de tudo, principalmente animais mortos e/ou abandonados ainda filhotes, uma moradora falou que não convêm enterrar cachorro que quando morrem devem ser abandonados. Muitas pessoas de outros lugares quando trocam móveis ou eletrodomésticos costumam descartar no Saladeiro. Restos de Construção são muitos encontrados, visto que, muitos locais dacidade têm terrenos que tem a placa que aceitam restos de construção. Outros resíduos citados em menor número foram carro de bebê, fogão, bolsas e lixo doméstico (Figura 5). 
Que tipos de residuos são encontrados na comunidade?

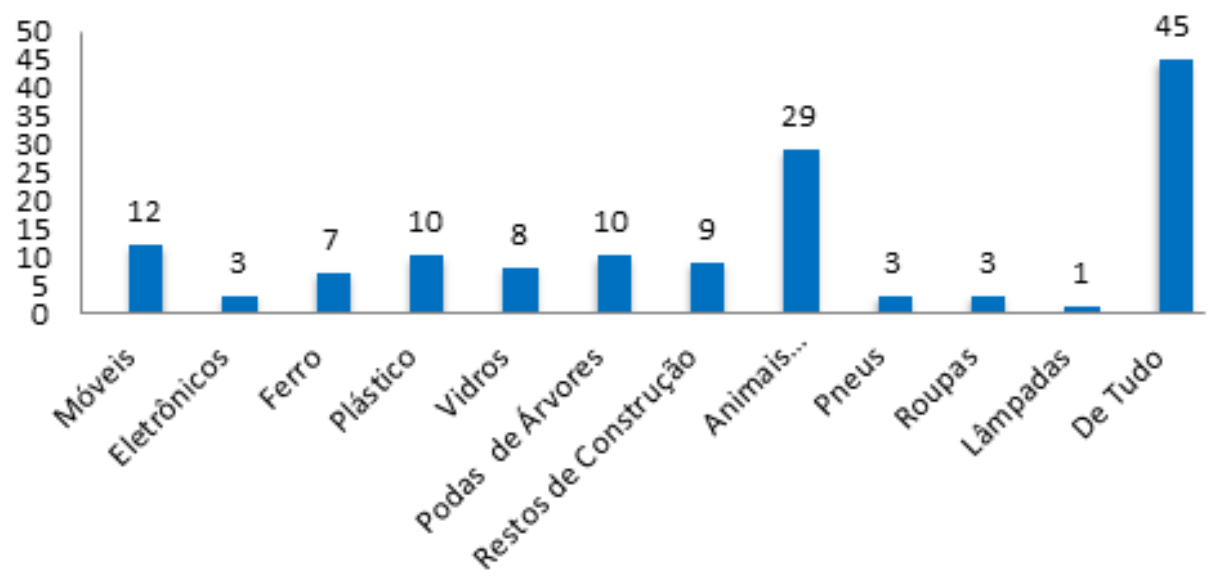

Figura 5 - Resposta da pergunta 5 sobre os tipos de resíduos que são encontrados no Bairro Saladeiro. Quaraí, 2014.

Fonte: Autores

Na pergunta 6 - Em sua residência alguém faz uso de medicamentos e aparelhos descartáveis?

Muitos utilizam medicamentos ou aparelho descartável ou reaproveitado como a bombinha para asma (Figura 6).

Em sua residência alguém faz uso de medicamento ou aparelho descartável?

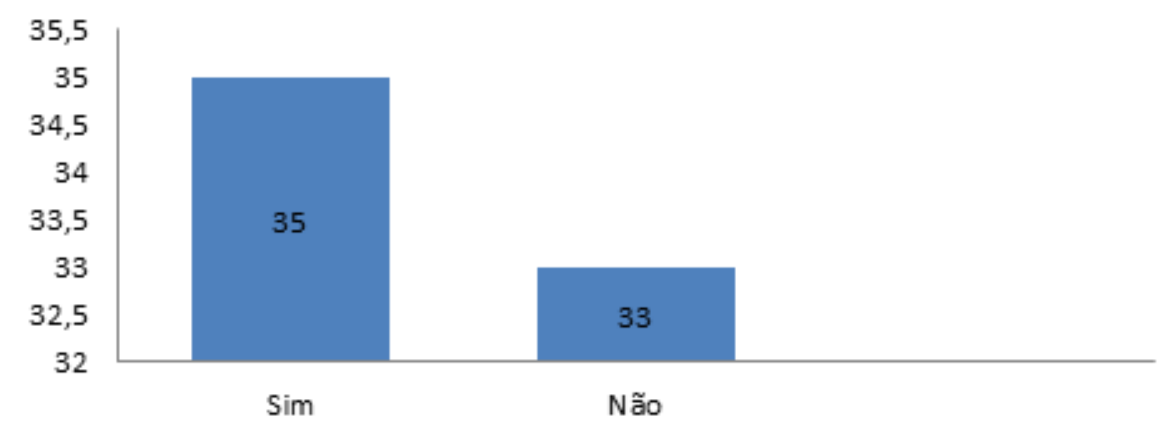

Figura 6 - Respostada pergunta 6 em relação ao uso de medicamento e/ou aparelho descartável. Quaraí, 2014. Fonte: Autores

Na pergunta 6 - De que forma são descartados esses resíduos (medicamentos e/ ou aparelhos)?

Muitos moradores recebem medicamentos controlados e/ou com a dosagem exata, o excedente é entregue para a agente de saúde e secretaria ou posto de saúde, a farmácia tem um posto de recolhimento poucos casos queimam ou descartam no lixo e na pia (Figura 7). 


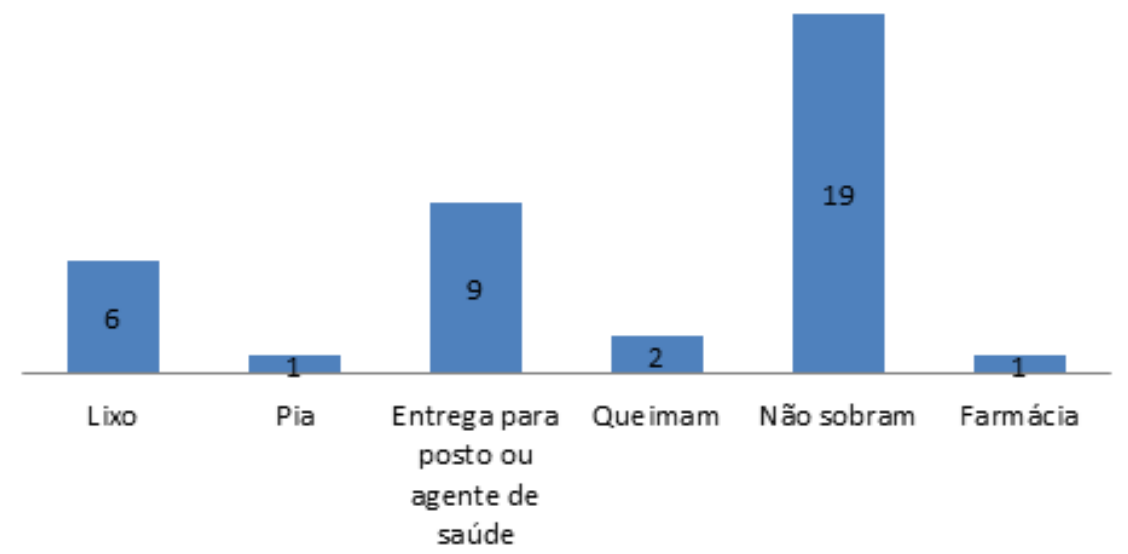

Figura 7 - Respostada pergunta 6 sobre a forma de descarte dos resíduos de remédios e/ou aparelhos da comunidade do Saladeiro. Quaraí, 2014.

Fonte: Autores

Na pergunta 7- Que ações poderiam contribuir para evitar o acúmulo de lixo?

As duas alternativas sugeridas no diagnóstico foram: Mais pontos de coleta de resíduos na comunidade e Criar um posto de coleta na comunidade para o acúmulo de resíduos e posterior recolhimento dos mesmos. Entretanto, durante a conversa surgiram outras sugestões dos moradores do Saladeiro como o famoso "Bota fora" no qual, a prefeitura, através da Secretaria de Obras do Município passa no bairro com caminhões com a finalidade recolher os resíduos existentes nos pátios das casas como eletrodomésticos, colchões etc. Com o tempo muitos moradores acabariam descartando a céu aberto em algum local inapropriado no próprio Saladeiro ou em algum outro local.

Outros sugeriram o uso de containers em determinados lugares como na ponte do Saladeiro, por exemplo, para alguns seria necessário uma fiscalização mais rígida com direito a multa. Visto que, o código de posturas do município prevê vários casos na qual se enquadraria o problema dos resíduos no bairro. Para vários moradores, outra sugestão seria um trabalho de conscientização e educação ambiental (Figura 8). Muitos moradores estão satisfeitos com o trabalho de coleta realizado pelo município e consideram suficiente a coleta do lixo três vezes por semana.

Que ações poderiam contribuir para evitar o acúmulo de lixo?

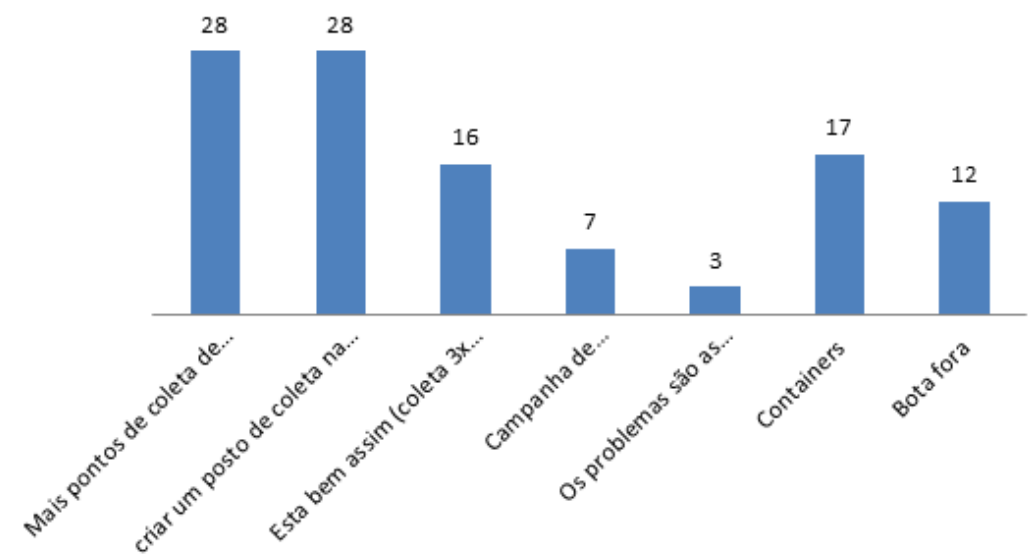

Figura 8 - Respostada pergunta 8 em relação as diversas formas que podem evitar o acúmulo de lixo. Quaraí, 2014.

Fonte: Autores 
Na pergunta 9 - Você sabe que o lixo acumulado pode servir de foco de doenças como a Dengue e servir de abrigo de animais como rato, escorpião, cobra, etc...?

Todos entrevistados confirmam ter conhecimento dos riscos e consequências.

Na pergunta 10 - Como você usa as águas do rio Quaraí?

A maioria não utiliza a água, alguns utilizam para tomar banho com os amigos, outros pescam e uma minoria utiliza para lavar o cachorro, por exemplo, conforme os dados da figura 9.

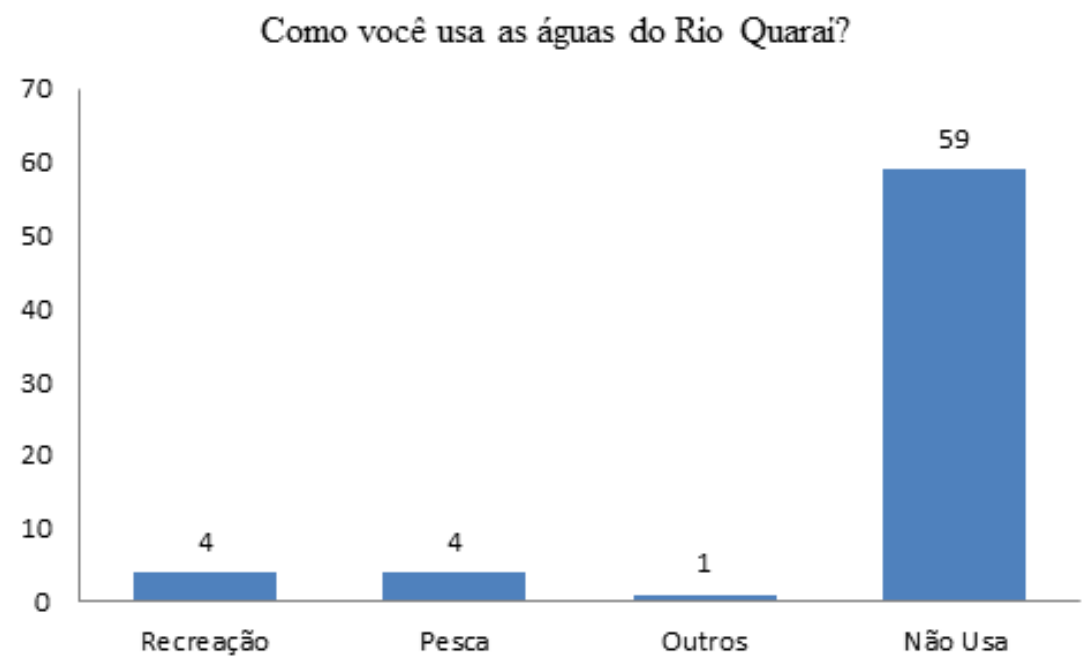

Figura 9 - Resposta da pergunta 10 acerca das formas de uso da água do Rio Quaraí. Quaraí, 2014. Fonte: Autores

Na pergunta 11 - Você sabe que o lixo jogado nas ruas e nas margens do rio pode contaminar as águas do Rio Quaraí?

É possível afirmar pelos dados que $100 \%$ dos moradores têm consciência que tudo que depositarem de resíduos no ambiente vai parar nas margens e consequentemente irá contaminar o Rio Quaraí. Ao afirmarem ter conhecimento das consequências do lixo nas margens como a contaminação das águas e as enchentes que já aconteceram no bairro, como na Figura 10 e Figura 11, de uma casa próxima a E.M.E.F. Emílio Callo.

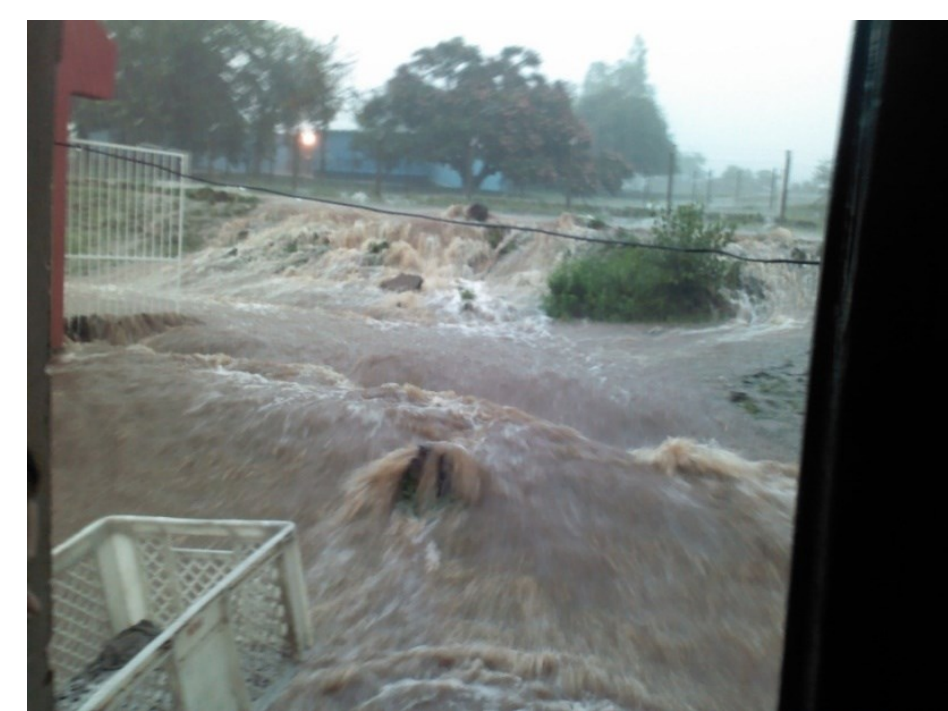

Figura 10- Enchente na Rua AscânioTubino: Dados da comunidade do Saladeiro. Quaraí, 2014. Fonte: Autores

Um morador da Rua AscânioTubino com a casa invadida pela enchente tentando proteger a casa e a família da água. 


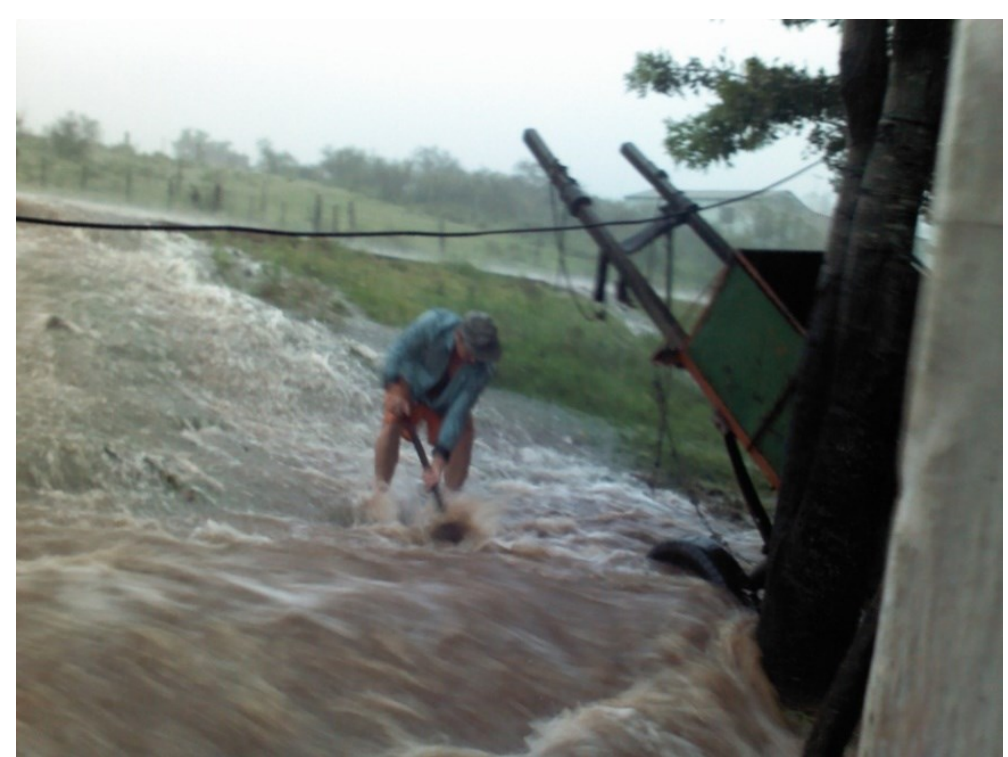

Figura 11 - Dados da comunidade do Saladeiro, Quaraí, 2014.

Fonte: Autores

\section{Na pergunta 12 - Como você poderia ajudar a melhorar o seu bairro?}

Muitos moradores optaram por uma ou duas opções, ou seja, eles colocam o lixo para recolhimento em horário próximo ao recolhimento da prefeitura e como comentado anteriormente nos questionamentos da pergunta 8, ou eles denunciariam a colocação do lixo através do telefone da secretaria de obras conforme consta nas placas distribuídas pelo local, outras maneiras citadas pelos moradores como: uma senhora que colabora varrendo a rua em que mora a mais de 40 anos e chamando a atenção dos vizinhos que sujam a rua ou colaborando quando ocorre a campanha do bota fora descartando colchões e eletrônicos que não utilizam por exemplo (Figura12).

\section{Como você poderia ajudar a melhorar o seu bairro?}

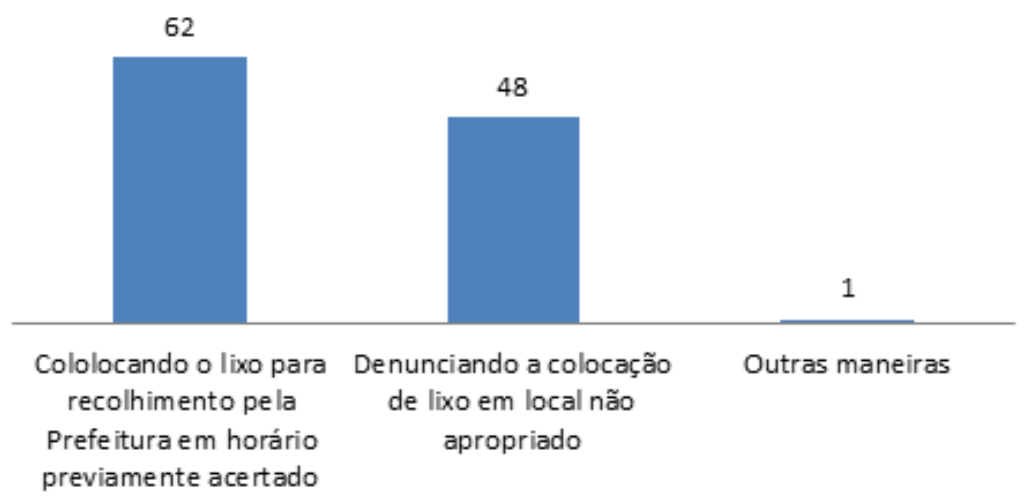

Figura 12 - Resposta da pergunta 12 a respeito das possíveis maneiras de melhorar o bairro da comunidade do Saladeiro. Quaraí, 2014.

Fonte: Autores

Na pergunta 13 - O que você gostaria de ter em seu bairro?

Muitos moradores gostariam ter uma área de lazer nas ruinas até mesmo para seus filhos terem onde brincar, um local com aparelhos de ginástica com existem em alguns bairros e vilas e o Posto de Saúde é outro ponto que os moradores sentem necessidade embora tenha um médico duas vezes na semana na E.M.E.F Emílio Callo os moradores não tem assistência médica nos demais dias, o Posto de Saúde indicado para eles fica localizado na vila Lauro Macedo (Matadouro) ou quando chove o deslocamento fica difícil ou com difícil acesso visto que a ponte 
sobe. (Figura13). Sendo um dos bairros mais antigos, o calçamento e o saneamento deixam a desejar.

O que você gostaria de ter em seu bairro?

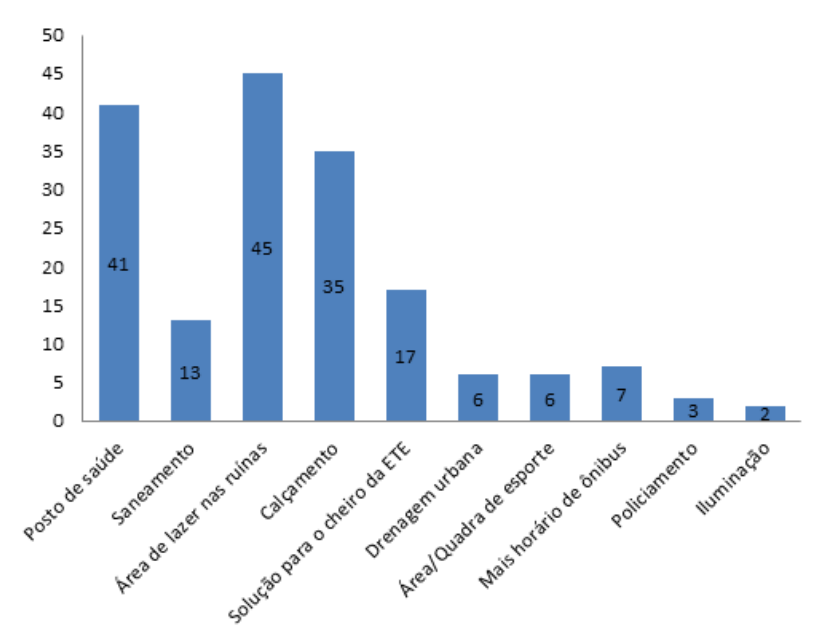

Figura 13 - Resposta da pergunta 13 da comunidade do Saladeiro em relação ao que gostariam de ter no bairro. Quaraí, 2014.

Fonte: autores

O cheiro da Estação de Tratamento de Esgoto é desagradável principalmente nas ruas AscânioTubino, São João Batista do Quaraí, no corredor municipal, uma moradora da Rua São Carlos esta preocupada com a instalação de uma Estação de Bombeamento de Esgoto em frente a sua casa. A CORSAN está solucionando o problema com a adição de um produto que pulveriza um produto que dá um cheiro agradável, muitos moradores alegam que o cheiro desagradável esta diminuindo comparando há meses atrás.

Outra questão que a população esta descontente são com os horários de ônibus, muitos alunos que estudam em outras escolas com, por exemplo, alunos da EJA (Educação de Jovens e Adultos), precisam vir de moto táxi ou a pé à noite, visto que, os moradores reclamam da falta de iluminação e policiamento.

Na pergunta 14 - Qual o comprometimento de vocês em relação às melhorias desejadas?

A maioria do moradores quando questionados se tudo que eles sugerem acontecer qual o comprometimento deles muitos disseram que ajudariam a cuidar, manter limpo ou proteger. Apenas uma moradora achou dificil se comprometer em qualquer aspecto.

Na pergunta 15 - Esses assuntos são discutidos em casa?

A maioria conversa em casa com a família sobre os problemas no bairro e o acúmulo de resíduos, outros não conversam e muitos poucos conversam às vezes (Figura 14).

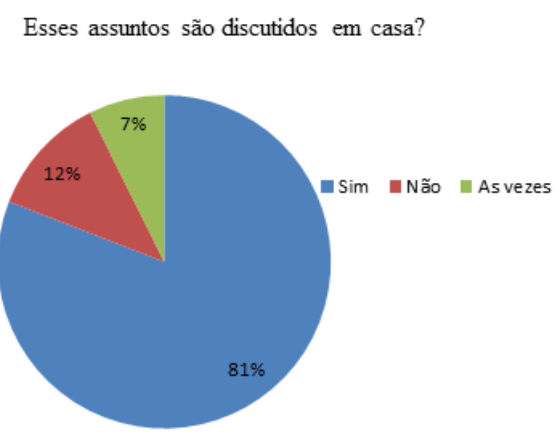


Figura 14 - Resposta da pergunta 15 sobre os assuntos discutidos em casa sobre resíduos e problemas no bairro da comunidade do Saladeiro. Quaraí, 2014.

Fonte: Autores

Na pergunta15 - Que meio de comunicação você ouve ou lê?

A grande maioria escuta rádio entre elas Quarai, Salamanca e Tchê, programa de televisão como: telejornais poucos usam a internet ou leem jornais e apenas 2 não assistiam Televisão , não liam jornal, nem internet, nem rádio apenas escutavam hinos religiosos ou tocadiscos (Figura 15).

Que meio de comunicação você ouve ou lê?

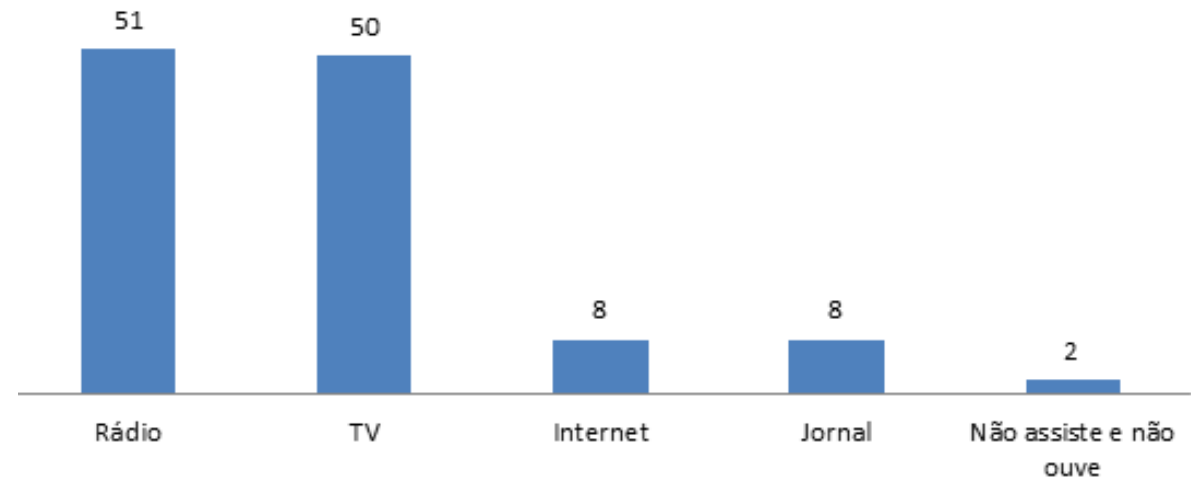

Figura 15- Resposta da pergunta 15 acerca dos meios de comunicação que os moradores tem preferência na comunidade do Saladeiro. Quaraí, 2014

Fonte: Autores

Na pergunta 16- Em que ano em casa e/ou bairro esses assuntos foram discutidos?

A maioria da população do Saladeiro, "tem raízes lá", ou seja, existem ascendentes de segundo grau, primeiro grau e descendentes. Muitas observações sobre o local é feita há muitos anos, alguns se mudaram pra lá há pouco tempo (Figura16).

Em que ano em casa e/ou bairro estes assuntos foram discutidos?

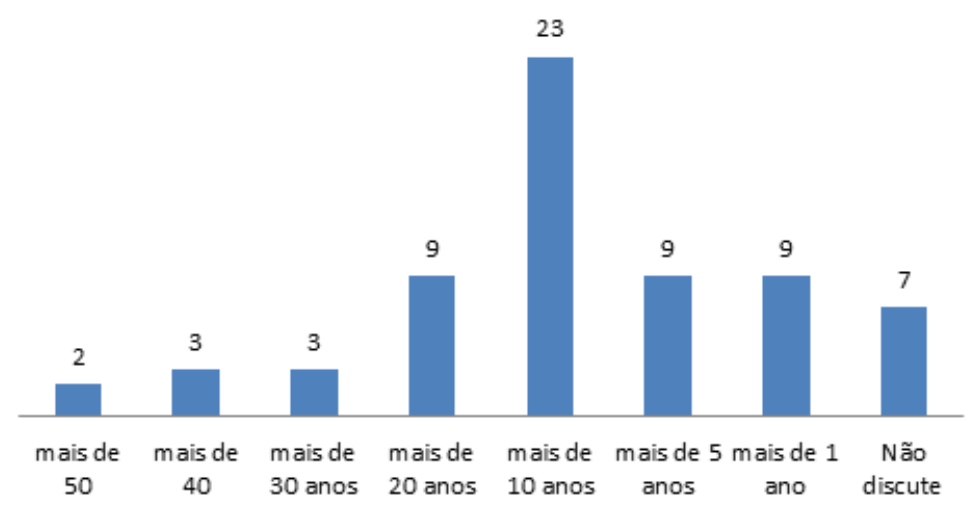

Figura 16 - Respostada pergunta 16 acerca de quanto tempo os assuntos são discutidos em casa e/ou bairro na comunidade do Saladeiro. Quaraí, 2014

Fonte: Autores

\section{Conclusão}


Os órgãos públicos têm interesse em realizar a atividade da limpeza das margens, entretanto a demora esta ocorrendo devido as condições meteorológicas. Mas em relação à limpeza das margens do rio não foi possível concretizar esta proposta inicial.

A Lei Municipal No 1.782, De 25 de Janeiro de 2000 capítulo III artigos 83, 84, 85 e 103 que abrange a problemática dos resíduos na cidade.

Os resultados do presente estudo sugerem que:

É possível concluir que devido às escolas, meios de comunicação, trabalhos realizados pela vigilância sanitária no combate a dengue todos tem conhecimento e consciência que as ações a pequeno, médio ou longo prazo geram consequências, ou seja, se eles mantiverem o ambiente limpo e saudável não haverá vetores de doenças e não será um fator que irá colaborar com enchentes e que os moradores têm consciência na grande maioria que o bairro precisa de melhorias, estão dispostos a colaborar para elas.

Através do questionário foi possível perceber o que eles pensam a respeito do ambiente que vivem e o quanto se preocupam com ele ou não e o que eles observam que acontece ao seu redor. A atividade prevista no projeto que era o mutirão de limpeza foi uma proposta que apesar do interesse dos órgãos em realizar não aconteceu como o esperado apenas no Uruguai, com o apoio da comunidade artiguense coletaram $14 \mathrm{~m}^{3} \mathrm{de}$ resíduos, o projeto Piloto sendo binacional, terá continuidade.

\section{Agradecimentos}

Agradeço primeiro a Deus que sempre me iluminou e me guiou.

Depois a minha orientadora, Prof. Dra.Cibele, pela compreensão e ajuda nesse longo caminho da conquista do conhecimento.

A todos que, direta ou indiretamente, contribuíram para a realização deste trabalho.

\section{Referências}

CARVALHO, Isabel Cristina de Moura. A Invenção Ecológica: narrativas e trajetórias da educação ambiental no Brasil. Porto Alegre: Editora da UFRGS, 2004.

DEUS, Ana Beatris Souza, ÍNDICE DE IMPACTO DOS RESÍDUOS SÓLIDOS URBANOS NA SAÚDE PÚBLICA (IIRSP): METODOLOGIA E APLICAÇÃO. Vol. 9 - N ${ }^{\circ}$ 4 - out/dez 2004, 329-334 Disponível em: <http://www.scielo.br/pdf/esa/v9n4/v9n4a09.pdf>. Acesso em: 3 dez. 2014.

MEDRONHO, R. A. et al. Epidemologia: . São Paulo: Atheneu, 2009.

MENEGAT, R.et al. Desenvolvimento Sustentável e Gestão Ambiental. Porto Alegre: editora UFRGS, 2004.

SILVA, Márcia Nazaré. A educação ambiental na sociedade atual e sua abordagem no ambiente escolar. In: Âmbito Jurídico, Rio Grande, XV, n. 99, abr 2012. Disponível em: $<$ http://www.ambito-juridico.com.br/site/?n_link=revista_artigos_leitura\&artigo_id=11367 >. Acesso em: $11 \mathrm{dez} .2014$.

VOLKMER, Márcia Solange. "Onde Começa ou Termina o Território Pátrio". (Especialização em Pós Graduação em História)-Universidade do Vale Rio dos Sinos, São Leopoldo, 20. 